\title{
Identifying the Types of Logistic Collaboration in SCM: A Study of Indian Automobile Manufacturing Companies
}

\author{
Asad Ullah ${ }^{1,2}$ \\ ${ }^{1}$ Department of Business Administration, Aligarh Muslim University, Uttar Pradesh, India \\ 2 Department of Management Studies, Middle East College, Muscat, Oman \\ Correspondence: Asad Ullah, Department of Management Studies, Middle East College (MEC), P.C. No 124, P.O. \\ Box No.79, Knowledge Oasis Muscat, Al Rusayl, Sultanate of Oman.
}

Received: December 20, 2019

Accepted: January 28, 2020

Online Published: February 11, 2020

doi:10.5430/jms.v11n1p26

URL: https://doi.org/10.5430/jms.v11n1p26

\begin{abstract}
In the context of supply chain, collaboration is relatively a very broad and encompassing term and as such needs further clarification. This study aims to identify the types of logistic collaboration in the Indian automobile manufacturing companies' vis-à-vis their supply chain management. This paper seeks to report the results of the survey conducted within the Indian automobile manufacturers regarding the type of collaborative practices in their supply chain and tries to illustrate how the size of the company, nature and the various segments affects their decisions regarding the choice of the type of collaborative practices. The paper fulfils the gap in the literature by examining the type of collaborative practices within the Indian automobile manufacturers and will thus be beneficial to the logistics managers and support further empirical research work in this field.
\end{abstract}

Keywords: automotive industry, logistics, collaboration, supply chain management, manufacturers

\section{Introduction}

Over the last two decades, the concept of collaboration has gained importance in industries as well as academic circle. In much literature, it has been referred as the driving force behind the efficient and effective supply chain management and considered as an ultimate core capability. However, much discussion is on the benefits that collaboration brings in to the supply chain and the collaborative SCM practices are emerging as a path that the companies can follow for successful and sustainable business operations. Anthony (2000) has defined collaboration as two or more organizations coming together and sharing the responsibility of planning, management, execution and evaluation of performance. According to Simatupang and Sridharan (2002,p.19) "a collaborative supply chain simply means that two or more independent companies work jointly to plan and execute supply chain operations with greater success than when acting in isolation."

The basic logic behind collaboration is that a single firm or company cannot compete by itself successfully (Richey, 2005). This is so because there has been increase in competition and the customers have become more demanding. The main reason for the firms entering into inter firm collaborative arrangement is the sharing of the risks and rewards and the basic objective being the high performance achievement, which cannot be achieved, while operating individually. Some of the steps that have been suggested by the academicians and practitioners for achieving the goals of collaborative SCM are the identification and agreement between the supply chain partners about their roles, defining of opportunities and objectives, developing a detailed plan of work and performance measurement.

Over the years, the concept of supply chain collaboration has been beneficially utilized by several industries, the front runner being the manufacturing industry especially the automobile manufacturing industry followed by the retail industry (Landry, 1998). For example, Wal-Mart shares its up-to-date sales and inventory information with its suppliers to reduce order cycle time and enables it to take stocking decisions. Due to this initiative both the parties gain. While Wal-Mart receives better retail price and a reduction in lost sales and stocking cost, the suppliers are able to replenish goods as they are sold, the chances of stock outs are minimized and brand loyalty is improved (Simatupang and Sridharan, 2002).

Also in the automotive industry collaboration has led to the globalization of supply chains and the manufacturing of complicated products, being sold at a lesser price. However, supply chain management in the automotive industry is 
amongst the most demanding of any industry as mass customization and the reduction of inventory pose greater challenges.

Thus it can be said that. "Supply chain collaboration has become an integral part of supply chain management" (Matopoulos et al., 2007) and has made the transition from being a purely theoretical concept to becoming a widely adopted supply chain practice. In simple words "It can be understood as a process of decision-making among interdependent parties across the many tiers in the supply chain, which involves joint ownership of decisions and collective responsibility for outcomes" (Stank et al., 2001). It has been established by previous researches that intense collaboration between organizations lead to enhancement in performances and lack of it creates problems (Lee and Billington, 1992; Frohlich and Westbrook, 2001, Pagell, 2004).

According to Barrat, 2004 "While the potential benefits have made collaboration a popular supply chain practice, its complex structure has left companies struggling with implementing, conducting and measuring collaborative supply chain initiatives" (Barrat,2004).

To conclude, it can be said that in spite of more than two decades of discussion about SCM and its promising effects, both by the industry and academic expert's, right set of SCM practices are rarely found in real existing supply chains. As rightly observed by Fawcett and Magnan, (2004), there is much talk about collaboration and its benefits by the industry practitioners as if it were the part of their organizations value structure but in reality very few companies are engaged in such practices. Furthermore, the researches concerning collaborative practices in SCM are out of place and are often based on single best practice cases only. Hence, there exists a gap between the theory and successful case stories on the one hand and survey based results on the other (Sandberg, 2005).

Hence, it is clear that more researches concerning collaboration based upon SCM is needed. In the present work, therefore, the researcher wishes to explore the logistics collaboration in SCM with main focus on automobile manufacturing companies in India.

\section{Review of Literature}

A literature review is the selection of available (both published and unpublished) on the topic, which contain information, ideas, data and evidence written from a particular standpoint to fulfil certain aims or express certain views on the nature of the topic and how it is to be investigated, and the effective evaluation of these documents in relation to the research being proposed. In this study, the extensive review of the literature has been conducted in order to identify the different variables related with the logistic collaboration in Supply chain with special focus on automobile manufacturing companies in India. Another purpose of conducting it was to identify the research gap so as to justify the necessity of conducting this research.

a) Collaboration in Supply Chain

According to Min et al., (2005) the concept of collaboration has been widely examined across disciplines like Psychology (Konczak, 2001; Stern and Hicks, 2000); Marketing (Gadde et al., 2003; Jap, 2001; Perks, 2000); Management (Cross et al., 2002; Sawhney, 2002; Singh and Mitchell, 2005); Sociology (Powell et al., 2005) and supply chain management (Holweg et al., 2005; Tuoninen, 2004). However, in this study the concept of collaboration has been reviewed within the supply chain context.

Collaborative practices in SCM have established itself as successful and sustainable business operations (Attaran and Attaran, 2007). Also, as per the survey conducted by In SCM review and computer science corporation (SCMR and CSC, 2004) collaboration has been cited as the most important issue. It is being increasingly promoted like "Silver Bullet" in many areas of SCM (Kampstra et al., 2006). Hence, there is no denial of the fact that collaborative practices in the logistics area have become the source of efficiency and decision-makers in the manufacturing and retailing industry have understood it.

According to (Chan et al., 2003) the emphasis on the effectiveness of Supply chain in its entirety has eliminated the boundaries of the single firms and has promoted them for collaboration between supply chain partners, leading to the establishment of strong relationships with each other. Therefore, Myhr and Speakman (2005) have described it as " $A$ critical linking pin, as greater specialization brings in more of integration in the overall supply chain". Taking the broader view Bahinipati et al., (2009) has defined it as "A business agreement between two or more companies at the same level in the Supply chain or network in order to allow greater ease of work and cooperation towards achieving a common objective".

In the words of Whipple et al., (2002) it means partners working together, in a trustful, loyal and mutual environment aimed at reducing costs, misuse of equipment and resources and improving performance. It is seen as a powerful 
instrument in achieving effective and efficient supply chain management (Fu and Piplani, 2004; Mentzer et al., 2000). Collaboration in supply chain has been conceptualized in various ways by researchers, as it can range from very shallow transactional focused to highly integrated close relations (Goffin et al., 2006); from collaborative communication to supplier development ( $\mathrm{Oh}$ and Rhee, 2008) or from inward facing to outward facing (Frohlich and Westbrook, 2001).

b) Levels of Collaboration

According to Arshinder and Deshmukh (2008) terms such as co-ordination, cooperation, collaboration and integration are considered to be similar in supply chain. However, Kampstra et al., (2006) considers it as a sequence of business initiatives carried out by likeminded collaborating partners and has divided it into four levels.

Level 1: "Communication"- here the goal of the partners is to achieve improvement in productivity and sharing of information through simple IT applications.

Level 2: "Co-ordination"- It involves intra and inter entity co-ordination of processes and its main purpose is the synchronisation of flows and automation of certain routine decision making processes for improving speed and accuracy. Here, the main focus remains on dealing with physical and policy constraints and additional investment in IT infrastructure becomes a necessity.

Level 3: "Intensive Collaboration"- It involves collaborative members intensively for improving the strategic decision making and enhancement of innovation in the supply chain.

Level 4: "Partnerships"- It involves extended financial linkages like sharing of investments and profits.

c) Types of Collaboration

In order to innovate within their supply chain firms enter into relationships. Various authors have called these types of relationships by various name like inter- organizational collaboration as joint ventures; Strategic alliances; Strategic alliances and inter -firm cooperation etc.

\subsection{Joint Ventures}

They are used to develop new market opportunities where the local party contributes in the form of market knowledge, labor and networks and the firm looking for new market provides goods and services, marketing strategies and financial resources.

\subsection{Strategic Alliances}

These are type of long term inter- firm relationship in which two or more partners indulge in sharing of resources, knowledge and capabilities with the objective of enhancing the competitive position of each partner.

\subsection{Co-operative Arrangements}

Co- operative arrangements are sought by many organizations with other organizations due to fast technological changes, organizational strategies, and competitive environment. According to Cousins (2002) the rationale behind cooperative efforts lies on sharing of both tangible and intangible resources, collaboration and business goals like efficiency, competitive advantage and survival, through redesigning of process and products.

According to Bowersox et al., (2000) due to ever changing global market and fierce competition, the traditional arm's length relationships are no longer considered to be effective. Therefore, it is not surprising that most of the companies quickly adopted themselves to this emerging trend of supply chain collaboration, which Lapide (1999) has classified into three major types. They being

- Manufacturer/ Supplier Collaboration

While collaborating with suppliers, the manufacturers can reap benefits in the areas of new product development, order fulfilment and capacity planning.

- Manufacturer/ Customer Collaboration

Collaborative relationship between manufacturers and customer (Distributors, wholesalers and retailers) can take place in the areas of demand planning and inventory replenishment.

- Collaboration with Third party and Fourth Party Logistics

While focusing jointly on planning of logistics activities, collaboration between companies and third party logistics (3PL) providers and fourth party logistics providers can take place.

Further, elaborating on the levels and types of collaboration found in the SCM literature, Barratt (2004) has 
presented the directions in which collaborative relationship can be formed i.e. either vertical or horizontal collaboration. In this he has identified "The four different potential relationship partners, suppliers and customers on the vertical axis and complementors or competitors on the horizontal plane". In addition, a new form of collaboration has also been identified called lateral collaboration, which is a form of combined relationship linking the benefits of vertical and horizontal collaboration (Mason et al., 2007).

\subsection{Virtual Collaboration}

It refers to a temporary tightly coupled collaborative effort between independent entities i.e. suppliers, customers, competitors linked by telecommunication technology. It helps in accessing the global market, cost sharing and skills.

In this study, the researcher purposes to explore the logistics collaboration activities being performed by Indian automobile manufactures (registered under SIAM) in managing their supply chains. Further, from the focal companies perspective (automobile manufacturers), three types of collaboration will be looked into i.e. where both the supplier as well as the customer are involved with the focal company (which is a triadic collaboration) or dyadic collaboration with either a supplier or a customer, as shown by the Figure 1 below:

Triadic collaboration where both Suppliers and Customers are involved

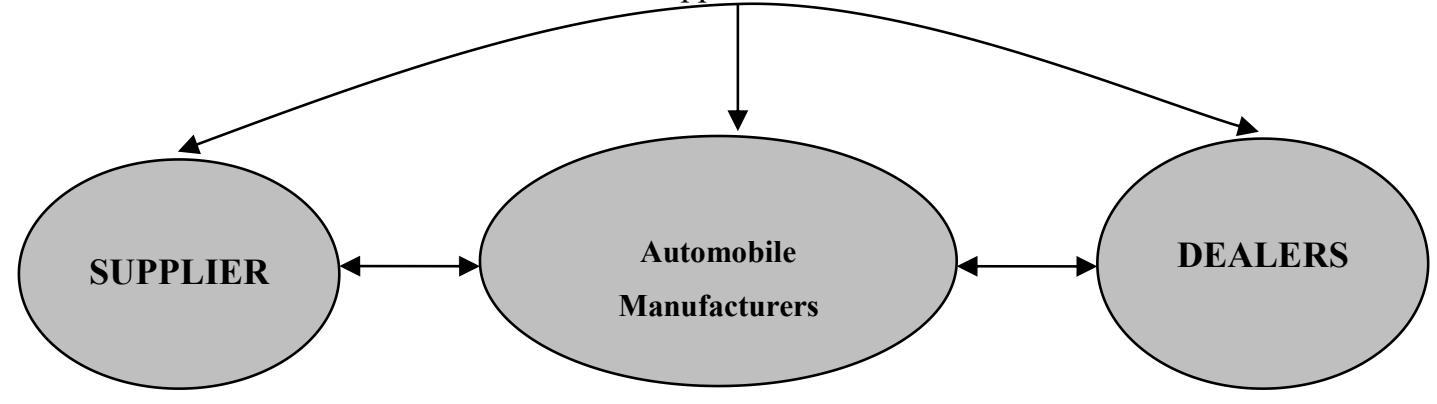

Dyadic Collaboration with supplier

Dyadic Collaboration with customer

Figure 1. The chosen perspective in the study

Source: Sandberg, Erik: 2005.

From the literature survey it has been found that companies can enter into several forms of collaboration like horizontal collaboration, internal collaboration etc. It has been felt by the researcher that it is beyond the scope of the study to investigate all the types. Thus in order to narrow down the scope of the present study only external collaboration in vertical direction (i.e. collaboration with suppliers and customers) would be investigated which is shown by the Figure 2 as:

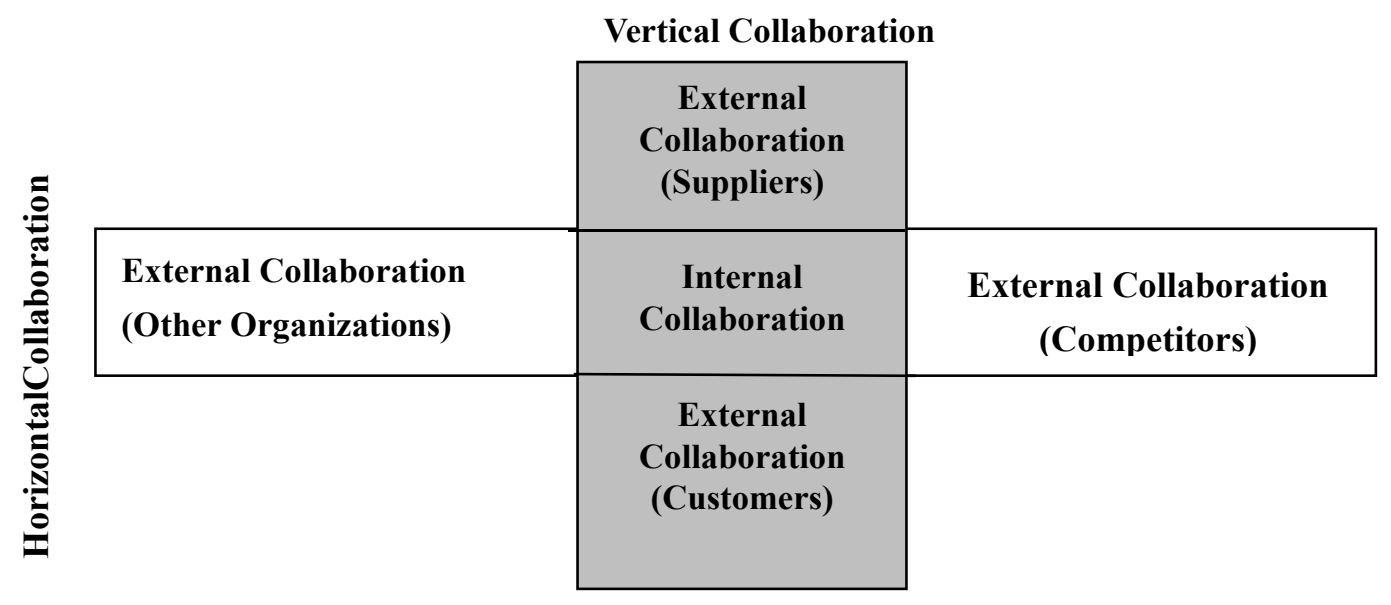

Figure 2. Different types of collaboration

Source: Barratt, 2004, p.32. 
Also, it has been found that in many researches the word collaboration has been used interchangeably with "cooperation" and "co-ordination" but organizational studies and marketing related texts show that these terms describe the different levels of supply chain relationships, leading up to supply chain collaboration. According to David and Byung (2003), there are four levels in all. The most basic level is "Arms- length" relationship, which may grow into second level "cooperation" and later "coordination" and finally into "collaboration". In this study, however, the researcher purposes to explore the highest level of commitment between / among supply chain participants that is supply chain collaboration.

On the basis of the literature surveyed by the researcher it is found out that almost all the automobile manufacturers use mostly 2PL providers (an asset-based carrier that owns the means of transportation) for their logistics operations, therefore the collaboration between the automobile manufacturer and third party logistics providers (3PL) or fourth party logistics providers (4PL) is not considered here.

\section{Method}

Research methodology is the research process or the procedural framework within which the research is conducted. According to Leedey and cited by Remenyi et al, (1998), it is "an operational framework within which the facts are placed so that their meaning may be seen more clearly". This study is mainly based on quantitative research methods which focus on numbers and frequencies rather than on meaning and experience. It provides information which is easier to analyse statistically. However, this method is criticized for not providing an in depth description.

a) Objective of the study

The objective of this study is to identify the type of collaboration when the automobile manufacturing companies collaborate logistically in their supply chain (manufacturer- customer, manufacturer- supplier and manufacturer-supplier-customer) in the context of India.

\section{b) Problem Statement}

The auto motive industry in India has become the centre of attention of the manufacturing sector across the globe. Over the years, the automotive industry in the world has changed its location preferences towards the developing economies like Brazil, India and China, and these countries are evolving as the manufacturing hub. The automobile-manufacturing scenario in India has significantly been altered due to the entry of global auto -majors. On one hand, the adoption of international technology and design has enabled the automotive industry to compete globally but on the other hand it has also exposed it to various challenges.

c) Research Hypotheses

Research hypotheses are a predictive statement, capable of being tested by scientific methods (Kothari, 2004). The Hypotheses $\left(\mathrm{H}_{01}\right.$ to $\left.\mathrm{H}_{03}\right)$ have been formulated in this research to show the differences if any between the type of collaboration chosen by the company across the sizes of the company, types of ownership and the type of segment in which the automobile manufacturing companies deals with.

$\mathrm{H}_{01}$ : Significant differences do not exist between the types of collaboration chosen by the company across its sizes.

$\mathrm{H}_{02}$ : Significant differences do not exist between the types of collaboration chosen by the company across its type of ownership.

$\mathrm{H}_{03}$ : Significant differences do not exist between the types of collaboration chosen by the company across its type of segment.

d) Research Process

This research has been conducted as follows:

1. Information collected through extensive literature survey so that we could identify the types of logistic collaboration in supply chain with special focus on the automobile manufacturing companies in India

2. Generating various hypotheses to examine the differences identified through the literature.

3. Developing a questionnaire as a survey tool to collect data.

4. Analyzing the data obtained through the questionnaire to see the type of logistic collaboration in supply chain in the automobile manufacturing companies in India.

5. Interpreting the results of the data analysed and arriving at conclusions.

e) Research Design

A research design precisely specifies particular means and methods through which required information can be 
collected for structuring the research as well as seeking specific practical solutions to the problem (Kapoor and Kulsherstha, 2010). It is the step aimed at designing the research study in such a way that the essential data can be gathered and analysed to arrive at a solution. The following are the design considerations for this research in accordance with the guidelines suggested by (Sekaran, 2003).

\section{e.1) The type of Study}

This study is both exploratory and descriptive in nature. Initially, in this study the researcher has followed an exploratory research design, where it was used for discovering the general nature of the problem and variables related to it. The secondary data was also analysed and expert opinion was also sought which are common methods of conducting exploratory study. After that descriptive research design was used, that is typically concerned with determining the frequency with which something occurs or the relationship between two variables.

\section{- $\quad$ e.2) Time Horizon of the study}

This research study is a cross-sectional study because it aimed to collect data just once, over a period of months from October 2012 to November 2013 in order to address the research objectives.

\section{f) Data Collection}

The automotive industry comprises of automobile and auto component sectors. However, this research is only concerned about the automobile industry in India. Therefore, the data for this study was obtained from 36 Indian auto mobile manufacturing Companies. It is one of the major industrial sectors in India and key driver of the national economy. Being one of the largest industries in India, subsequent to the liberalization, the automobile sector has been described as the sun rise sector of the Indian economy due to tremendous growth witnessed during the last two decades. Also, this industry has for a long time had closely linked supply chains requiring collaboration between the supply chain partners, Zirpoli and Caputo (2002). The Indian automotive industry is also suitable for survey research as this study required a large sample size. Also, due to the nature of the questions the logistics managers were identified as being the single most knowledgeable person to provide the required information.

The method used to collect data in this research is the questionnaire survey. The questionnaire was developed in several stages. Firstly, a paper-based version of the questionnaire draft was pre tested with three subject experts and two industry experts. This was done to cross verify the contents, structure and nature of the questions asked in the questionnaire and improve validity (Mitchell, 1996). Then it was pilot tested, were it was send to the 46 logistics managers working in the automobile manufacturing companies (registered under SIAM) in India. Out of which 26 of them responded. Based on their valuable comments, the questionnaire was further refined and after some minor design changes, a web-based questionnaire was used to collect the data reported in this paper. Using the snow ball sampling technique of data collection, the questionnaires (Web-based) were emailed to the suitable respondents. The overall sample comprised 288 logistics managers of which 210 responded. While, after discarding the questionnaires with incomplete information, 192 responses were found suitable for further analysis giving a satisfactory response rate of $66.6 \%$.

\section{Results and Discussion}

It is the step where data is analysed statistically to see if the hypotheses can be substantiated. In order to analyse the data the researcher has used SPSS (Version 20) software and appropriate statistical tools. The analysis is divided into two parts. The first part describes the sample and the second part deals with the analysis based on the hypothesis relating to the type of logistics collaboration across size, type and segment of the auto mobile manufacturing companies.

\subsection{Description of the Sample}

\subsubsection{Group or Non-group of Companies}

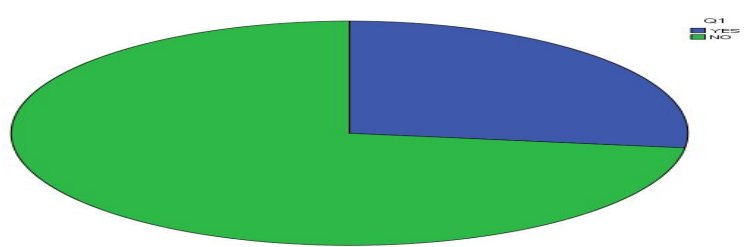

Figure 3. Showing the respondents belonging to the group or non-group of companies 
From the above description of the figure, it is evident that majority of respondents belonged to non-group of companies.

\subsubsection{Size of the Company on the Basis of Annual Turnover}

Table 1. Showing the sizes of the company on the basis of annual turnover

\begin{tabular}{llll}
\hline S.no. & Size of the company & Frequency & Percent \\
\hline 1. & Small & 129 & 67.2 \\
\hline 2. & Medium & 43 & 22.4 \\
\hline 3. & Large & 20 & 10.4 \\
\hline & Total & 192 & 100.0 \\
\hline
\end{tabular}

The above Table 1 shows that majority of the respondents $(67 \%)$ belonged to the small size companies, while approximately $22 \%$ belonged to the medium category and only about of $10 \%$ of them belonged to the large size companies.

\subsection{Nature of Ownership}

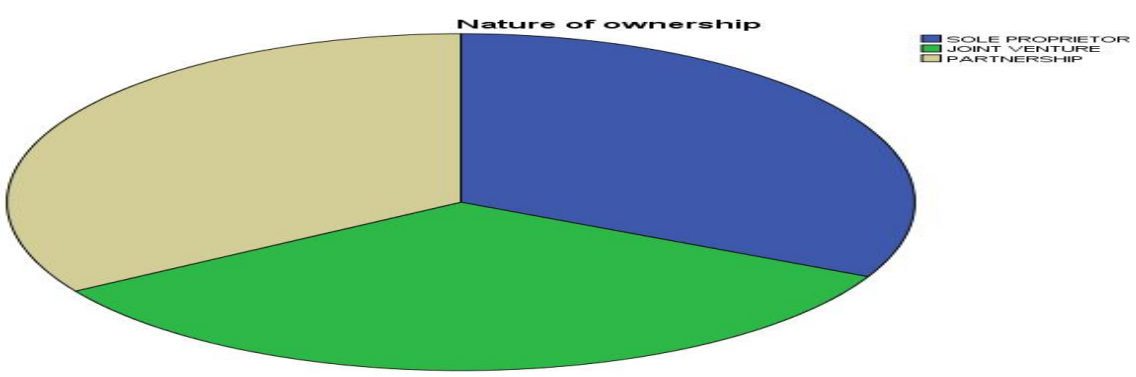

Figure 4. Showing the nature of type of ownership of companies

With regard to the type of ownership, it is evident that almost there are equal numbers of participants belonging to each category.

\subsection{Type of Segment in Which the Companies Operate}

Table 2. Showing the type of segment of the company

\begin{tabular}{lll}
\hline Type of segment & Frequency & Percent \\
\hline 2-Wheelers & 48 & 25.0 \\
\cline { 2 - 3 } 3-Wheelers & 43 & 22.4 \\
\hline Commercial Vehicles & 68 & 35.4 \\
\hline Passenger Vehicles & 33 & 17.2 \\
\hline Total & 192 & 100.0 \\
\hline
\end{tabular}

From the above table it is clear that majority of the respondents belonged to the commercial vehicles manufacturing companies, followed by two wheelers and three wheelers. 


\subsection{Type of Collaborative Relationship Practiced by the Companies}

Table 3. Showing the type of collaborative relationship practiced by the company

\begin{tabular}{llll}
\hline S. no. & Type of collaboration & Frequency & Percent \\
\hline 1. & Triadic & 96 & 50.0 \\
\hline 2. & Dyadic-Customers & 51 & 26.6 \\
\hline 3. & Dyadic-Suppliers & 45 & 23.4 \\
\hline & Total & 192 & 100.0 \\
\hline
\end{tabular}

From Table 3 it is evident that almost $50 \%$ of the respondents belonged to the companies which practiced triadic collaboration (Manufacturer - Supplier - customer), while about nearly $27 \%$ of the respondents belonged to the companies having dyadic relationship (manufacturer - customer) and rest of them belonged to the companies having (manufacturer- supplier) relationship only.

\subsection{Hypothesis Testing (Inferential Statistics)}

\subsubsection{Kruskal-Wallis Test}

The Kruskal-Wallis test is a nonparametric test used to compare three or more samples. It is used to test the null hypothesis that all populations have identical distribution functions against the alternative hypothesis that at least two of the samples differ only with respect to location (median), if at all. Here the purpose of this test is to explore significant differences, if exist between the type of collaboration chosen by the company and the effects of collaboration across the sizes of the company, types of ownership and types of segment in which the automobile manufacturing companies deal with.

\subsubsection{Kruskal-Wallis Test Based on Sizes of the Company}

$\mathrm{H}_{01}$ : Significant differences do not exist between the types of collaboration chosen by the company across its sizes.

Table 4. Summarized results of hypothesis testing using Kruskal-Wallis Test

\begin{tabular}{llllll}
\hline Type of collaboration & $\mathbf{N}$ & Chi-value & Sig & Results & Remarks \\
\cline { 1 - 2 } Triadic & 96 & & & & \\
\cline { 1 - 2 } Dyadic-Customers & 51 & & & & Rejected \\
\cline { 1 - 2 } Dyadic-Suppliers & 45 & & 0.000 & Significant & \\
\cline { 1 - 2 } Total & 192 & & & & \\
\hline
\end{tabular}

Significant difference was found to exist between the types of collaboration chosen by the company vis-à-vis there sizes. Hence, the hypothesis $\mathrm{H}_{01}$ is rejected.

$\mathrm{H}_{02}$ : Significant differences do not exist between the types of collaboration chosen by the company across its type of ownership.

Table 5. Summarized results of hypothesis testing using Kruskal-Wallis Test

\begin{tabular}{|c|c|c|c|c|c|c|}
\hline Type of collaboration & $\mathbf{N}$ & Chi- value & Sig & Results & Remarks & \\
\hline Triadic & 96 & \multirow{4}{*}{5.199} & \multirow{4}{*}{0.074} & \multirow{4}{*}{ Insignificant } & \multirow{4}{*}{$\begin{array}{l}\text { Failed } \\
\text { Reject }\end{array}$} & \multirow{4}{*}{ to } \\
\hline Dyadic-Customers & 51 & & & & & \\
\hline Dyadic-Suppliers & 45 & & & & & \\
\hline Total & 192 & & & & & \\
\hline
\end{tabular}


Significant difference was not found to exist between the types of collaboration chosen by the company vis-à-vis their types of ownership. Hence, the hypothesis $\mathrm{H}_{02}$ is failed to be rejected.

$\mathrm{H}_{03}$ : Significant differences do not exist between the types of collaboration chosen by the company across its type of segment.

Table 6. Summarized results of hypothesis testing using Kruskal-Wallis Test

\begin{tabular}{llllll}
\hline Type of Collaboration & N & Chi- value & Sig & Results & Remarks \\
\cline { 1 - 2 } Triadic & 96 & & & & \\
\cline { 1 - 2 } Dyadic-Customers & 51 & & & & \\
\cline { 1 - 2 } Dyadic-Suppliers & 45 & & 0.000 & Significant & Rejected \\
\cline { 1 - 2 } Total & 192 & & & & \\
\hline
\end{tabular}

Significant difference was found to exist between the types of collaboration chosen by the company vis-à-vis there types of segment. Hence, the hypothesis $\mathrm{H}_{03}$ is rejected.

\subsection{Inference}

The Kruskal - Wallis test revealed that significant differences existed between the type of collaboration chosen by the company across its size and the type of segment whereas no such difference was found to exist between it and the type of ownership of the companies.

\section{Conclusion}

The changes in SCM have been truly revolutionary and the pace of progress shows no sign of moderating. In our increasingly interconnected and interdependent global economy, the process of delivering supplies and finish goods and information and other business services from one place to another is accomplished by means of mind boggling technological innovation, clever new applications of old ideas, seemingly magical mathematics, powerful software and old fashioned concrete, steel and muscle. An end to end, top to bottom transformation of the 21 st century supply chain is shaping the agenda now and will continue to do so for years to come.

In this study it is reported that the non-group of companies (The companies not having subsidiaries) and small in size (on the basis of annual turnovers) mostly belonging to commercial vehicle, two and three wheeler segment are more inclined towards collaborative practices (Triadic in nature ) as compared to larger ones. Furthermore, the companies having joint venture and partnership type of ownership prefer to have more or less all kinds of collaborative relationships, which indicate that those who are already having some kind of partnerships are inclined further towards collaborative practices.

\section{Limitations}

The study is an attempt at exploring the various types of logistics collaboration in supply chain in the automobile manufacturing companies in India. Yet, the researcher feels that like any other empirical study there are certain limitations which may be considered and are listed as under:

$>$ The limitation of the accessibility to the respondents dictated the sample not to be larger than the present one; however it is still a very good sample size suitable for this type of study.

$>$ The sampling technique used was judgemental sampling which is a non-probability technique. Therefore, the representativeness of the sample is not known and hence the results should be used with caution.

$>$ The data for the study was collected from only one group of the respondents registered under automobile industry professional India. Therefore, it raises concern over the generazibility of the findings in India and also the other parts of the world.

$>$ The study does not proposes or test any model which could have been the addition and contribution to the existing knowledge in the field.

$>$ With regard to the general applicability of the findings some restrictions results from the sample characteristics. Therefore, the findings of the study need to be generalized with caution 


\section{Future Research Directions}

Based on this study, the following directions for futures research may be pointed out:

1. Specific studies investigating dyadic collaboration between supplier-manufacturer and between customermanufacturers can be undertaken. Further, the present study can be extended by taking into account the views from suppliers and customers regarding the collaborative practices in supply chains.

2. This study mainly focuses on logistic collaborative practices in supply chains of automobile manufacturing companies. However, further studies can be conducted involving other manufacturing sectors.

3. Comparative and case based studies can be undertaken specifically targeting few companies in order to analyse in depth the logistic collaborative practices adopted by them in their supply chains.

4. This work is an attempt to study logistic collaboration in vertical direction only. Therefore, more studies can be undertaken to investigate the logistic collaboration in supply chain directed internally and horizontally.

5. Specific and indepth study can be undertaken particularly relating to the process approach, role of information sharing and planning in the logistics collaboration in supply chains.

6. A similar kind of study may be undertaken for investigating the role of 3PL and 4PL service providers in the same context.

\section{Acknowledgements}

Gratitude can never be expressed in words but this is an honest attempt towards the same. I convey my gratefulness to all the respondents, who became the part of this study. Without their genuine responses this study would not have been possible.

\section{References}

Anthony, T. (2000). Supply chain collaboration: success in the new internet economy. Achieving Supply Chain Excellence through Technology (Vol. 2, pp. 41-4). Montgomery Research Inc., San Francisco, CA.

Attaran, M., \& Attaran, S. (2007). Collaborative supply chain management: The most promising practice for building efficient and sustainable supply chains. Business Process Management Journal, 13(3), 390-404.

Bahinipati, B. K., Kanda, A., \& Deshmukh, S. G. (2009, March 12). Horizontal collaboration in semiconductor manufacturing industry supply chain: an evaluation of collaboration intensity index, Computers \& Industrial Engineering. Retrieved from www.sciencedirect.com/science/article/B6V274,VTKKPV1/2/33cb88021beb0a6aa4645193f5573fff

Barratt, M. (2004). Understanding the meaning of collaboration in the supply chain. Supply Chain Management: An International Journal, 9(1), 30-42.

Bowersox, D. J., Closs, D. J., \& Keller, S. B. (2000). How supply chain competency leads to business success. Supply Chain Management Review, 4(4), 70-80.

Cousins, P. D. (2002). A conceptual model for managing long term inter-organisational relationship. European Journal of Supply Chain and Management, 8(2), 71-82.

Cross, R., Borgatti, S. P., \& Parker, A. (2002). Making invisible work visible. California Management Review, 44(2), $25-46$.

David, A., \& Son, B.-G. (2003, February). The Truth about Collaboration.

Erik, S. (2005). Logistics Collaboration in Supply Chains - A Survey of Swedish Manufacturing Companies, No. 93. Licentiate Thesis.

Fawcett, S. E., \& Magnan, G. M. (2004). Ten guiding principles for high-impact SCM. Business Horizons, 47(5), 67-74.

Frohlich, M. T., \& Westbrook, R. (2001). Arcs of integration: An international study of supply chain strategies. Journal of Operations Management, 19(2), 185-200.

Fu, Y., \& Piplani, R. (2004). Supply-side collaboration and its value in supply chains. European Journal of Operational Research, 152(1), 281-8.

Gadde, L.-E., Huemer, L., \& Hakansson, H. (2003). Strategizing in industrial networks. Industrial Marketing Management, 32(5), 357-64. 
Goffin, K., Lemke, F., \& Szwejczewski, M. (2006). An exploratory study of 'close' supplier - manufacturer relationships. Journal of Operations Management, 24(2), 189-209.

Holweg, M., Disney, S., Holmstrom, J., \& Smaros, J. (2005). Supply chain collaboration: making sense of the strategy continuum. European Management Journal, 23(2), 170-81.

Jap, S. D. (2001). Pie sharing' in complex collaboration contexts. Journal of Marketing Research, 38(1), 86-99.

Kampstra, R. P., Ashayeri, J., \& Gattorna, J. L. (2006). Realities of supply chain collaboration. The International Journal of Logistics Management, 17(3), 312-330.

Konczak, L. J. (2001). The process of business/environmental collaborations: partnering for Sustainability. Personnel Psychology, 54(2), 515-8.

Mason, R., Lalwani, C., \& Boughton, R. (2007). Combining vertical and horizontal collaboration for transport optimisation. Supply Chain Management: An International Journal, 12(3), 187-199.

Matopoulos, A., Vlachopoulou, M., Manthou, V., \& Manos, B. (2007). A conceptual framework for supply chain collaboration: empirical evidence from the agri-food industry. Supply Chain Management: An International Journal, 12(3), 177-86.

Mentzer, J. T., Foggin, J. H., \& Golicic, S. L. (2000). Supply chain collaboration: the enablers, impediments, and benefits. Supply Chain Management Review, 4(4), 52-80.

Min, S., Roath, A. S., Daugherty, P. J., Genchev, S. E., Haozhe, C., Arndt, A. D., \& Richey, R. G. (2005). Supply chain collaboration: what's happening?. International Journal of Logistics Management, 16(2), 237-56.

Myhr, N., \& Spekman, R. E. (2005). Collaborative supply - chain partnerships built upon trust and electronically mediated exchange. Journal of Business and Industrial Marketing, 179-186.

Oh, J., \& Rhee, S. K. (2008). The influence of supplier capabilities and technology uncertainty on manufacturer-supplier collaboration. International Journal of Operations \& Production Management, 28(6), 28.

Pagell, M. (2004). Understanding the factors that enable and inhibit the integration of operations, purchasing and logistics. Journal of Operations Management, 22(5), 459-487.

Perks, H. (2000). Marketing information exchange mechanisms in collaborative new product development. Industrial Marketing Management, 29(2), 179-89.

Powell, W. W., White, D. R., Koput, K. W., \& Owen-Smith, J. (2005). Network dynamics and field evolution: the growth of inter organizational collaboration in the life sciences. The American Journal of Sociology, 110(4), 1132-206.

Remenyi, D., \& Swartz, E. (1998). Doing Research in Business and Management. An Introduction to Process and Method. London: Sage.

Richey, R. G. (2005). Supply chain collaboration: what's happening?. The International Journal of Logistics Management, $16(2), 237-256$.

Sawhney, M. (2002). Don't just relate - collaborate. MIT Sloan Management Review, 43(3), 96.

Sekaran, U. (2003). Research method for business: A skill building approach (4th ed.). John Wiley \& Sons.

Stern, A. J., \& Hicks, T. (2000). The Process of Business/Environmental Collaborations: Partnering for Sustainability. Quorum, Westport, CT.

Tuominen, M. (2004). Channel collaboration and firm value proposition. International Journal of Retail \& Distribution Management, 32(4), 178-89. 